\title{
A COFECÇÃO DE UMA CARTILHA EDUCATIVA PARA O ENSINO DO CICLO DA ÁGUA
}

\section{LA COFECCIÓN DE UN FOLLETO EDUCATIVO COMO RECURSO DIDÁCTICO PARA LA ENSEÑANZA DEL CICLO DEL AGUA}

\section{THE COFECTION OF AN EDUCATIONAL BOOKLET FOR WATER CYCLE TEACHING}

Ewerton Henrique da Conceição ${ }^{1}$; Levi Araujo Bezerra ${ }^{2}$; Luiz Carlos Alves de Souza ${ }^{3}$

DOI: https://doi.org/10.31692/978-65-991061-3-2.129-133

\section{INTRODUÇÃO}

A água é um recurso de fundamental importância para a manutenção da vida no planeta, e falar da relevância dos conhecimentos sobre a água, em suas diversas dimensões, é falar da manutenção da espécie humana, da conservação da biodiversidade e das relações biogeoquímicas de interdependência entre os seres vivos e o meio ambiente.

A presença ou ausência de água determina a história, interfere drasticamente em fatores culturais e hábitos comportamentais, determina o futuro de gerações. O planeta terra não teria se transformado em ambiente adequado para a vida sem a água. Desde sua origem, os elementos hidrogênio e oxigênio se combinaram para dar origem ao elemento-chave da existência da vida. (BACCI e PATACA, 2008)

A água é o único composto químico a estar presente na Terra de maneira simultaneamente sob as formas sólida, líquida e gasosa. Estes três estados desempenham papéis no funcionamento do planeta que é comumente chamado de planeta água. A água é constituída de moléculas que sofrem atração por coesão. Essas moléculas no estado líquido estão em constante movimentação, movendo-se verticalmente no sentido da atmosfera terrestre e horizontalmente no sentido da superfície terrestre. Essa agitação é proporcional à energia ou à temperatura direcionada sobre a água. Quando a temperatura se eleva, as moléculas aumentam a agitação da superfície tendem a escapar da massa líquida e ficam livres na atmosfera, em estado gasoso. (MIRANDA, et al, 2010)

Atualmente, a água passou a ser vista como um recurso hídrico e não mais como um bem natural, é usada de forma indiscriminada e quando uma fonte esgota, simplesmente é

\footnotetext{
${ }^{1}$ Licenciando em Ciências Biológicas, Universidade Federal de Pernambuco, ewerton.henri2013@gmail.com

${ }^{2}$ Licenciando em Ciências Biológicas, Universidade Federal de Pernambuco, levitj1.lab@gmail.com

${ }^{3}$ Mestre em educação agrícola, professor do Instituto Federal de Pernambuco Campus Vitória de Santo Antão, nagusto.eaf@hotmail.com
} 
encontrada outra, sem serem avaliadas as consequências ambientais em relação à quantidade e qualidade do que resta, somado ao aumento populacional no último século, a ocupação do solo, à poluição e contaminação dos corpos de águas superficiais e subterrâneos, levou a sociedade a uma crise profunda na qual ameaça a existência das próximas gerações, essa crise, é um dos mais graves problemas a serem enfrentados neste século.

Trabalhar a conscientização do cidadão em relação ao seu ambiente é um dos princípios fundamentais para que aconteça de fato gestão de recursos hídricos. Conhecer para preservar, um ditado tão comum, mas tão pouco levado à prática. Sem a educação a espécie humana não conseguirá desenvolver seus potenciais e cada vez mais será esmagada.

O presente estudo tem por objetivo descrever o processo de confecção de uma cartilha educativa na promoção da educação ambiental, como recurso didático no ensino do ciclo da água.

\section{FUNDAMENTAÇÃO TEÓRICA}

Segundo Victorino, (2007) quase toda a superfície do planeta Terra está coberta por água: água dos oceanos, água dos rios e lagos correspondendo a $1.370 .000 .000 \mathrm{~km}^{3}$ é constituída basicamente por dois tipos: água salgada dos mares e água doce. 97\% do total, é água salgada o que vem a ser impropria restando apenas uma pequena parcela para o consumo humano.

Os impactos da ação humana no ciclo hidrológico e na qualidade das águas são decorrentes de um conjunto de atividades humanas, como, por exemplo o direcionamento de boa parte da água para irrigação, abastecimento público, produção de hidroelétricas, turismo, pesca, transporte, navegação, mineração, recreação entre outros (TEIXEIRA et al, 2014).

Segundo Victorino, (2007) os grandes problemas ligados à água não acontecem por causa da natureza, mas sim pelo mau uso com desperdício, como exemplo em Londres, pela falta de manutenção em canos e dutos das tubulações de água, é perdida uma quantidade de água capaz de encher, diariamente, 300 piscinas olímpicas.

Amorim (2013), aponta que os modelos didáticos, são facilitadores contribuindo para a aprendizagem significava, pois permitem a participação ativa do estudante em seu processo de aprendizagem. Os modelos didáticos complementam o conteúdo dos livros (ORLANDO, et al., 2009, p. 2).

A cartilha é um recurso didático de grande importância para facilitar o entendimento dos conteúdos. As atividades remetem ao leitor um cenário mais próximo da realidade, e desta forma, ela possui um grande potencial para a promoção da educação ambiental, se tornando um 
agente facilitador e um importante instrumento educacional. (SILVA, 2017).

\section{METODOLOGIA}

A metodologia empregada na elaboração da cartilha foi baseada em algumas etapas: a escolha do tema; produção e seleção das ilustrações; preparo do conteúdo, tomando como base a literatura científica, elaboração da cartilha, avaliação do material, por profissionais da educação e por fim o uso da cartilha como recurso didático.

A primeira etapa ocorreu por meio da procura de trabalhos científicos, relacionando os temas "Ciclo da água"4 e "Educação ambiental", foi evidenciada baixa produção de estudos associando esses dois temas, as informações encontradas, foram utilizadas para direcionar o foco do tema, e na elaboração da cartilha.

A fase de produção e seleção das ilustrações, ocorreu em paralelo a fase de preparo do conteúdo, pois dessa forma, as imagens e o texto são complementares, possibilitando assim, um melhor entendimento do conteúdo.

O preparo do conteúdo foi embasado na literatura científica, para garantir a fidedignidade e confiabilidade das informações apresentadas. Alguns websites e livros foram acessados e utilizados como base para confirmar as informações da cartilha.

Na elaboração da cartilha, o conteúdo preliminar foi desenvolvido com o foco de apresentar apenas as informações consideradas essenciais. Esse conteúdo foi submetido ao trabalho de edição. O desenvolvimento dessa fase foi baseado em critérios previamente estabelecidos para todo o processo de produção da cartilha, isto é, a facilidade de leitura e clareza dos conteúdos apresentados.

A cartilha passou por avaliação de quinze estudantes do curso de Licenciatura em Ciências Biológicas da UFPE-CAV, que já haviam cursado as disciplinas de fundamentos da educação, didática e avaliação da aprendizagem, foi submetida também à avaliação de professores especialistas na área da educação, que fazem parte do quadro de servidores da UFPE-CAV.

\section{RESULTADOS E DISCUSSÕES}

A avaliação do material produzido, por parte dos quinze estudantes do curso de Ciências Biológicas da UFPE-CAV e professores especialistas na área da educação da UFPE-CAV, que aprovaram suas informações. Em relação à linguagem, foi avaliada a conveniência e a facilidade

\footnotetext{
${ }^{4}$ Link para acesso das páginas da cartilha: https://drive.google.com/drive/folders/134AahdSeUI91er5Tvdkv_v8TD8fQH_mv?usp=sharing
} 
de compreensão e os conceitos mais importantes estavam sendo abordados de maneira clara e objetiva, voltado para atender o público alvo (crianças dos anos iniciais do ensino fundamental).

Figura 1: Capas da frente e do verso da cartilha.

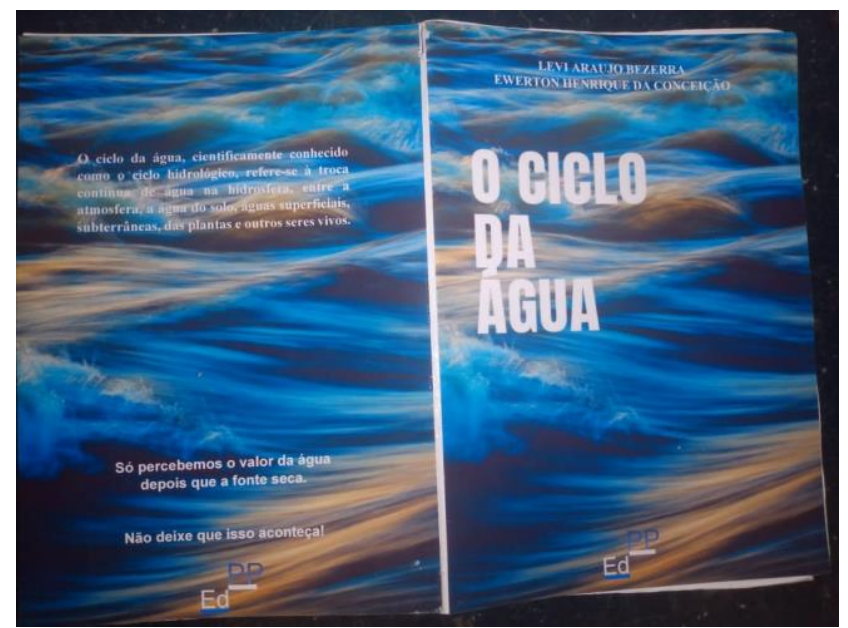

Fonte: Própria (2019)

Silva (2017), afirma, que a cartilha é um recurso didático de grande importância para facilitar o entendimento dos conteúdos. As atividades remetem ao leitor um cenário mais próximo da realidade, e desta forma, ela possui um grande potencial para promover da educação ambiental, tornando-se um agente facilitador no processo de aprendizagem. Corroborando também, Amorim (2013) e Orlando, et al., (2009, p. 2) apontando que os modelos didáticos, contribuem para a aprendizagem significava, pois permitem a participação do estudante em seu processo de aprendizagem.

\section{CONCLUSÕES}

O presente estudo, teve como intuito apresentar o processo de confecção da cartilha o ciclo da água e despertar o interesse sobre o ciclo da água, apresentando um método de ensino interessante capaz de incentivar o conhecimento e promover a educação ambiental.

A cartilha pode ser considerada um material didático de popularização da ciência e uma importante ferramenta de educação ambiental, na promoção da sensibilização da população para a importância da água na manutenção da vida no planeta.

\section{REFERÊNCIAS}

AMORIM, A.S. A influência do uso de jogos e modelos didáticos no ensino de biologia para alunos de ensino médio. 2013. 49f. Monografia (Licenciatura em Ciências Biológicas) Universidade Aberta do Brasil, Centro de Ciências e Saúde, Universidade Estadual do Ceará, Ceará, 2013.

Disponível em: 
http://www.uece.br/sate/index.php/downloads/doc_download/2146-biobeberibeamorim>. Acesso em: 29 jul. 2019.

BACCI, Denise de La Corte; PATACA, Ermelinda Moutinho. Educação para a água.Estud. av., São Paulo , v. 22, n. 63, p. 211-226, 2008 . Disponível em: $<$ http://www.scielo.br/scielo.php?script=sci_arttext\&pid=S0103-

$40142008000200014 \& \operatorname{lng}=$ en\&nrm=iso $>$. Acesso em 30 Jun, 2019.

MIRANDA, Ricardo Augusto Calheiros de; OLIVEIRA, Marcus Vinicius Siqueira de; SILVA, Danielle Ferreira da. Ciclo hidrológico planetário: abordagens e Conceitos. GEOUERJ, Rio de Janeiro, v. 1, n. 21, p. 109-119, 2010. Disponível em:< https://docplayer.com.br/36488154Ciclo-hidrologico-planetario-abordagens-e-conceitos.html>. Acesso em: 11 Ago. 2019.

ORLANDO, T.C. et al. Planejamento, montagem e aplicação de modelos didáticos para abordagem de biologia celular e molecular no ensino médio por graduandos de ciências biológicas. Revista brasileira de ensino de bioquímica e biologia molecular, v.1, n.1, p.117, 2009. Disponível em: < http://bioquimica.org.br/revista/ojs/index.php/REB/article/view/33/29 >. Acesso em: 02 Ago. 2019.

SILVA, Katia Araújo et al. Elaboração de uma cartilha como material educativo para preservação da tartaruga verde (chelonia mydas) em itaipú, niterói, rio de janeiro. Revista Presença, [S.1.], v. 2, p. 35-58, aug. 2017. ISSN 2447-1534. Disponível em: <http://revistapresenca.celsolisboa.edu.br/index.php/numerohum/article/view/117>. Acesso em: 01 ago. 2019.

TEIXEIRA, Vanessa; LINDNER, Josiele; PRESTES, Angelina Martins. Relato da experiência da oficina pedagógica na escola: "o ciclo da água e a necessidade de preservá-la". Revista Eletrônica de Geografia, v.6, n.17, p. 126-137, out. 2014. Disponível em < http://www.observatorium.ig.ufu.br/pdfs/6edicao/n17/7.pdf>. Acesso em: 11 Jun, 2019.

VICTORINO, Célia Jurema Aito. Planeta água morrendo de sede: uma visão analítica na metodologia do uso e abuso dos recursos hídricos. Porto Alegre : EDIPUCRS, 2007.Disponivel em: < http://www.pucrs.br/edipucrs/online/planetaagua.pdf> acesso em: 10 Ago 2019. 